Journal of Systems Science and Information

Feb., 2015, Vol. 3, No. 1, pp. 77-85

DOI: $10.1515 /$ jssi-2015-0077

\title{
Port Multi-Period Investment Optimization Model Based on Supply-Demand Matching
}

\author{
Guangtian ZHAO \\ Faculty of Management and Economics, Dalian University of Technology, Dalian 116024, China \\ E-mail: zhaoguangtian@hotmail.com \\ Keyi WANG \\ Faculty of Management and Economics, Dalian University of Technology, Dalian 116024, China \\ E-mail: wangky@dlut.edu.cn \\ Fangping YU \\ School of Transportation Management, Dalian Maritime University, Dalian 116026, China \\ E-mail: yufangping1981@126.com \\ Haibo KUANG \\ School of Transportation Management, Dalian Maritime University, Dalian 116026, China \\ E-mail:dlutkhb@139.com
}

\begin{abstract}
With China's economic slowdown and port low-level repeated construction, China ports are facing the problem of overheated investment. In this paper, using the port supply-demand balance and comprehensive cost as the two main optimization goals, the ecological carrying capacity and the port profit-loss as the constraints, the port multi-period investment decision optimization model is built up by means of dynamic programming. Sustainable development ability about port supplydemand matching and ecological carrying capacity are considered into the decision-making model, which is used to solve the existing literature disadvantage of port investment planning decision based on operation efficiency and benefit. It helps to prevent the port resources waste and ecological environment destruction, and has the reality instruction significance.
\end{abstract}

Keywords port; supply-demand matching; investment optimization; ecological carrying capacity; dynamic programming

\section{Introduction}

Since 2000, China's economy and external trade's rapid development have stimulated the demand of port industry greatly. Many ports competed to plan and invest on big deep water

Received June 30, 2014, accepted August 13, 2014

Supported by National Natural Science Foundation of China "Research on Low Carbon Port Formation Mechanism and Evaluation Mode (71273037)", Development Program for Changjiang Scholars and Innovative Research Team "Port Coordination Development and Green Growth (IRT13048)", Liaoning Province University Innovation Team Support Program Funding "Research on the Port of Low Carbon Intelligent and Key Technology (LT2013011)", and China Ministry of Transport Traffic Soft Science Project"Research on the Development of Chinese Port Regionalization and Best Mode (2013-322-225-240) 
ports, which promoted the development of our nation's external trade. "Port Law of People's Republic of China" and "National Port Plan" were put forward in 2006, which was a milestone to Chinese ports development. However, with economic growth slowing down in recent years, some port investment problems are exposed, such as aimless expansion, ambiguous fixed position and port strand line resource utilization unreasonably, etc. Those problems can be owed to the low level reconstruction problem. The irrational port investment seems to be more obvious in the future ${ }^{[1-3]}$.

The existing literatures about port investment optimization object is focused on the port berth, quay, loading and unloading equipment, etc ${ }^{[4]}$. Yang ${ }^{[5]}$ set up a comprehensive cost port investment model from the port operation cost view, which included the cost of loading and unloading berths, equipment cost, labor cost and the ship cost, and so on. And illustrated with examples of the model in determining the best handling equipment in port the scale of investment and the number of loading and unloading equipment. Li et al. ${ }^{[6]}$ tried to use genetic algorithm combined with neural network, measure feasibility investment on port berth, and the establishment of a berth investment decision model, and an example of calculation and analysis with satisfactory results. Ding ${ }^{[7]}$ simulation combined with integer programming, dynamic investment optimization method was proposed for container port handling equipment with multi terminal, with the goal of minimizing the total cost of container terminals in port, the best overall model from the viewpoint of each terminal for overall arrangement, get the port handling equipment wharf, the annual investment plan, therefore, closer to the actual port. Wang and Jiang ${ }^{[8]}$ used two-layer programming method to make decision on regional port logistics system's inland distributing center and transportation network. Allahviranloo and Afandizadeh ${ }^{[9]}$ considered the freight volume, investment cost, handling capacity and the port transportation network as well as the world's major ship as the constraint condition, the fuzzy integer programming model of container port ship berth in different periods and investment optimization. These researches defined the key direction of port investment, and it can make a certain effect on port planning construction, but it was obvious that it cannot quantify port investment optimization.

From the above analysis, we can see that the existing literatures have got some fruit, but the existing port investment optimization decision-making theories are not mature and perfect yet. There are two unsolved problems: One is that the port investment optimization theory does not consider the sustainable development ability, such as ecological carrying capacity, etc ${ }^{[10,11]}$. The other is that the port investment optimization theory only considers the costs and benefits of different investment strategies, ignoring the factor of the supply-demand matching ${ }^{[12-14]}$. This kind of research is more complex, more challenging.

From the overall optimization of multi period investment strategy point of view, by using the dynamic programming method ${ }^{[15,16]}$, this paper builds the port investment optimization model based on supply-demand matching, to make up for existing port investment theory and model disadvantage.

The paper proceeds as follows. In Section 1, the existing research status is summarized. Section 2 constructs the research method to optimize the multi-period investment port. In Section 3, an optimization model of multi-period port investment is set up based on two ob- 
jective function supply-demand matching and the comprehensive cost, and the constraints of ecological carrying capacity, the operation of the port profit and loss. Section 4 provides an example analysis. Section 5 is the conclusion.

\section{The Thought of Port Multi-Period Investment Optimization}

Port investment has some features of big-scope, long construction and recovery period ${ }^{[13]}$. Chinese ports are in a period of "pursuing scope, big and all-sided, unspecialized". At the same time, the port investment has the characteristics of construction and the recovery period is long, the port investment planning cycle is also relatively long ${ }^{[17]}$. Therefore, this paper establishes dynamic programming of multi period investment optimization model. The thought of model is: With the port supply-demand matching and comprehensive cost as the main optimization goals, the port of profit and loss, ecological carrying capacity and other conditions as constraints, we build the optimization model by means of dynamic programming.

\section{The Model}

\subsection{The Parameter Variables}

The model basic parameters are defined as follows:

$k$ : The period of port investment planning is divided into $K$ sections $(k=0,1, \cdots, K$, it is usually divided by berth construction cycle, for example, 3 or 5 years can be a section);

$n$ : The years that a period contains;

day: Port's work days in a year;

$l$ : The type of the berth $(l=1,2, \cdots, L)$, for example, the container berth 4000TEU, 8000TEU, and so on, it is supposed that the bigger $l$ is, the bigger the berth is;

$T_{l}$ : The ship type according with the $l$ th berth type, such as the container 4000TEU, 6000TEU, 8000TEU, 10000TEU, 12000TEU, and so on;

$b_{l}$ : The construction and equipment cost of the $l$ th berth (contain the initial excavation cost, the cost of equipments such as suspension bridge, and so on);

$m_{l}^{1}$ : The percentage of the operation cost of the lth type berth in every section to berth construction and equipment cost $b_{l}$;

$m_{l}^{2}$ : The percentage of the dredging cost of the $l$ th type berth in every section to berth construction and equipment cost $b_{l}$;

$r$ : The interest rate per year, because the planning period is long, here the rate can be defined by the long national debt rate, such as that of 10 years or 20 years;

$l$ : The center of container port inland hinterland $(l=1,2, \cdots, L)$;

$q_{l 0}: q_{i}^{m}$ : The amount of the $i$ th berth of port $m$ in 0 moment;

$j$ : The route of the port group $(j=1,2, \cdots, J)$;

$c_{k j}$ : The route $j$ average container transportation cost in the $k$ th period. Because most routes are fixed, so we can define and predict it according to port's historical data and the related data of shipping market;

$x_{k j}^{l}$ : The amounts of ships in the route $j$ to berth type $l$ in the $k$ th period. We can use the historical statistics data and market survey to the freight traffic volumeand combine some factors such as the related policy, resource distribution, economy arrangement adjustment, the 
trend of international shipping market, and so on, we estimate and predict its amount;

$\lambda_{k}^{l}$ : The work days of ship type $T_{l}$ to berth type $l$ in the $k$ th period. It is decided by the loading and unloading days, the amount and efficiency of loading and unloading suspension bridge, port's working hours per day;

$R_{k}$ : The unit throughput net loading and unloading profit in the $k$ th period. It can be gotten by port loading and unloading profit minus cost;

$A_{l}$ : The biggest amount of the $l$ th berth that is confined by the natural condition (shore ling length, ecological carrying) of port, which can be defined by port management authority according to some factors such as port environment, city planning, and so on.

The intermediary decision-making parameters are defined as follows:

$S_{k l}$ : The port total supply throughput amount of the $l$ th berth type in the $k$ th period;

$D_{k l}$ : The port total demand throughput amount of the $l$ th berth type in the $k$ th period;

$C_{\text {trans }}$ : The port transportation cost during the planning period;

$C_{f a c}$ : The port construction and equipment cost during the planning period;

$C_{\text {ope }}$ : The port operation and dredging cost during the planning period;

Inc: The port total profit during the planning period;

$d_{k}$ : The port total throughput amount of in the $k$ th period;

The final decision-making parameter is defined as follows:

$q_{i}^{k m}$ : The amount of the $l$ th port berth type that need to be newly built in period $k$. It is a nonnegative integer.

\subsection{The Objective Function}

This research mainly consider the port investment planning from a new angle of supplydemand matching and comprehensive cost, which is considered as a optimization objective function.

\section{1) Port supply-demand matching optimization objective function}

In fact, the port investment should first consider the port supply-demand matching currently and in the future. Each port berth must be fully utilized, in other words, is to ensure that the port in the actual operation not neither in "sunned terminal" status nor in "long queue", where each period the port supply and demand equalization. The large ships can only dock at large berths. However, the smaller ships not only can berth in a small, but also can be docked at large berths, so its expression can be written as

$$
\min \left|F_{k l}\right|=\left|\left(S_{k l}-D_{k l}\right) / S_{k l}\right|, \quad \forall k, l
$$

In this formula, the port total supply throughput amount of the $l$ th berth type in the $k$ th period $S_{k l}$ is expressed by

$$
S_{k l}=\sum_{j=1}^{J} x_{k j}^{1} \lambda_{k}^{1}+\sum_{j=1}^{J} x_{k j}^{2} \lambda_{k}^{2}+\cdots+\sum_{j=1}^{J} x_{k j}^{l} \lambda_{k}^{l}
$$

The port total demand throughput amount of the $l$ th berth type in thekth period $D_{k l}$ is expressed by

$$
D_{k l}=n \times d a y \times\left[\left(q_{10}+\sum_{i=0}^{k} q_{1 i}\right)+\left(q_{20}+\sum_{i=0}^{k} q_{2 i}\right)+\cdots+\left(q_{l 0}+\sum_{i=0}^{k} q_{l i}\right)\right]
$$




\section{2) Port comprehensive cost optimization objective function}

The port comprehensive cost is consist of transportation cost, construction and equipment cost, operation and dredging cost, which consider the cost of shipper, the goods owner and the port. The expression is as follows:

$$
\min C_{\text {trans }}+C_{\text {fac }}+C_{\text {ope }}
$$

In this formula, the port transportation cost during the planning period $C_{\text {trans }}$ is expressed by

$$
C_{\text {trans }}=\sum_{k=1}^{K} \sum_{j=1}^{J} \sum_{l=1}^{L} \frac{1}{(1+r)^{n k}} c_{k j} T_{l} x_{k j}^{l}
$$

We suppose that the berth construction and equipment cost happened in the initial stage of period, the port construction and equipment cost during the planning period $C_{f a c}$ is expressed by

$$
C_{f a c}=\sum_{k=1}^{K} \sum_{l=1}^{L} \frac{1}{(1+r)^{n(k-1)}} b_{l} q_{l k}
$$

Similarly, we suppose that the berth operation and dredging cost happened in the initial stage of period, the port operation and dredging cost during the planning period $C_{\text {ope }}$ is expressed by

$$
C_{\text {ope }}=\sum_{l=1}^{L}\left[b_{l}\left(m_{l}^{1}+m_{l}^{2}\right) \sum_{k=1}^{K} \frac{1}{(1+r)^{n(k-1)}}\left(q_{l 0}+q_{l 1}+\cdots+q_{l k}\right)\right]
$$

Other factors need to be considered in the port investment from the aspect of country, such as port development promote region development and raise the employment rate, and other equipment cost (such as road, storehouse, extensible stacking machine, and so on). In this study, because the target is search the best berth investment planning, we consider the cost factors that related to ship type, berth, etc. Other indirect factors that are indirectly related to the planning are not considered in this paper.

\subsection{Constraint Conditions}

The model has three constraint conditions: Ecological carrying capacity constraint, port cost and profit constraint and integer programming constraint.

\section{1) Ecological carrying capacity constraint}

Environment cost should be considered in port investment. Because of its particularity, in ordinary situation, port investment construction has a great influence to the peripheral environment, which is irreversible ${ }^{[10,11]}$. Port ecological carrying capacity is determined by the length of shoreline, the protecting cost of sea creature's living environment, the amount of possible pollution accident, the producing traffic noise, and so on ${ }^{[10,11]}$. In other words, the port investment planning construction size is limited, and cannot surpass the max ecological carrying capacity. 
Suppose that the port investment planning construction size as $W$, the max ecological carrying capacity as $f\left(c_{1}, c_{2}, c_{3}, c_{4}, \cdots\right)$, where $c_{1}$ is length of shoreline, $c_{2}$ is sea creature's living environment, $c_{3}$ is pollution accident, $c_{4}$ is traffic noise, and so on.

So that port investment planning construction size cannot surpass the max size that under ecological carrying capacity can be described as

$$
W \leq f\left(c_{1}, c_{2}, c_{3}, c_{4}, \cdots\right)
$$

We place emphasis on ecological carrying capacity in port investment planning construction, which can reach the goal of protecting shoreline resource and ecological environment. Because port investment is mainly used to berth construction, according to formula (8), this brief simplifies ecological carrying capacity constraint as follows:

$$
q_{l 0}+\sum_{k=1}^{K} q_{l k} \leq A_{l}, \quad \forall l
$$

\section{2) Cost and profit constraint}

Port investment cost must be taken back in a certain period. In this paper, we suppose that the port investment cost and the income at least can be maintained balanceable, and we suppose that the port's profit cannot be totally gotten until the end of this planning period, that is,

$$
\operatorname{Inc}-\left(C_{f a c}+C_{\text {ope }}\right) \geq 0
$$

In this formula, the port total profit during the planning period Inc is expressed by

$$
\text { Inc }=\sum_{k=1}^{K} \frac{1}{(1+r)^{n k}} R_{k} d_{k}
$$

The port total throughput amount of in the $k$ th period $d_{k}$ is expressed by

$$
d_{k}=\sum_{j=1}^{J} \sum_{l=1}^{L} T_{l} x_{k j}^{l}, \quad \forall k
$$

\section{3) Integer programming constrains}

$$
q_{l k} \in Z+
$$

where $Z+$ stands for the integers bigger than or equal to 0 .

\subsection{Port Investment Optimization Model}

Combing the above objective function and constraint conditions, we get the port multiperiod investment optimization model (14) based on dynamic programming method:

$$
\min \left\{\frac{\sum_{j=1}^{J} x_{k j}^{1} \lambda_{k}^{1}+\cdots+\sum_{j=1}^{J} x_{k j}^{l} \lambda_{k}^{l}-n \times d a y \times\left[\left(q_{10}+\sum_{i=0}^{k} q_{1 i}\right)+\cdots+\left(q_{l 0}+\sum_{i=0}^{k} q_{l i}\right)\right]}{\sum_{j=1}^{J} x_{k j}^{1} \lambda_{k}^{1}+\sum_{j=1}^{J} x_{k j}^{2} \lambda_{k}^{2}+\cdots+\sum_{j=1}^{J} x_{k j}^{l} \lambda_{k}^{l}} \mid\right\}, \forall k, l
$$




$$
\min \left\{\begin{array}{c}
\sum_{k=1}^{K} \sum_{j=1}^{J} \sum_{l=1}^{L} \frac{1}{(1+r)^{n k}} c_{k j} T_{l} x_{k j}^{l}+\sum_{k=1}^{K} \sum_{l=1}^{L} \frac{1}{(1+r)^{n(k-1)}} b_{l} q_{l k} \\
+\sum_{l=1}^{L}\left[b_{l}\left(m_{l}^{1}+m_{l}^{2}\right) \sum_{k=1}^{K} \frac{1}{(1+r)^{n(k-1)}}\left(q_{l 0}+q_{l 1}+\cdots+q_{l k}\right)\right]
\end{array}\right\}
$$

Constraint conditions

$$
\begin{aligned}
q_{l 0} & +\sum_{k=1}^{K} q_{l k} \leq A_{l}, \quad \forall l \\
& \sum_{k=1}^{K}\left[\frac{1}{(1+r)^{n k}} R_{k} \times\left(\sum_{j=1}^{J} \sum_{l=1}^{L} T_{l} x_{k j}^{l}\right)\right] \\
\geq & \sum_{k=1}^{K} \sum_{l=1}^{L} \frac{1}{(1+r)^{n(k-1)}} b_{l} q_{l k} \\
& +\sum_{l=1}^{L}\left[b_{l}\left(m_{l}^{1}+m_{l}^{2}\right) \sum_{k=1}^{K} \frac{1}{(1+r)^{n(k-1)}}\left(q_{l 0}+q_{l 1}+\cdots+q_{l k}\right)\right] \\
q_{l k} & \in Z+
\end{aligned}
$$

The model (14) has three characteristics as follows: Firstly, it reflected the matching principle of port group supply and demand, which solves the problem of port unoccupied or overload operated. Secondly, it has considered port's ecological carrying capacity. Bringing ecological carrying capability into port investment optimization strategy reflected the idea of people oriented and protecting environment, which can optimize investment strategy efficiently. Thirdly, it reflected the principle that port investment and profit should be balanceable. By controlling port investment cost directly, it resolved the disadvantage of aimless investing for scopeneglecting port operational profit, and reflected the operational discipline of port investment efficiently.

\subsection{Solution}

The model (14) is a bi-objective multi-period dynamic integer programming model. The second objective can be weighted in stratified or basis, or by using backtracking algorithm convert into integer linear programming, and its specific algorithm can see the the specific reference [15].

\section{Example}

\subsection{Data Collection}

It is supposed that we make investment planning from 2014 to 2024 for a container port in 2013, the planning is divided into 2 periods ( $K=2, k=1$ (2014-2018), $k=2$ (2019-2023)). There is 1 sea route, $J=1$. Through deep research and study, port planning department get the data needed, which is shown in Tables $1 \sim 5$, and according to the related data of the container port, we know that the proportion that operational cost to construction cost $m_{l}^{1}$ is $2 \%$ and the proportion that dredging cost to equipment cost $m_{l}^{2}$ is $1 \%$, respectively. Interest rate per year is $r=5 \%$. The amount of working days per year is day $=250$. 
Table 1 Different routes unit cost of container transport $c_{k j}$ (¥/TEU)

\begin{tabular}{ccc}
\hline Period $k$ & $k=1$ & $k=2$ \\
\hline Route $j(j=1)$ & 60 & 100 \\
\hline Table 2 & Container Handling Unit Net $R_{k}(¥ / \mathrm{TEU})$ \\
\hline Period $k$ & $k=1$ & $k=2$ \\
\hline$R_{k}$ & 15 & 10 \\
\hline Table 3 Ship loading and unloading capacity of different berths $\lambda_{k}^{l}$ (Day) \\
\hline Berth type $l$ & Period $k$ & \\
\hline$l=1$ & $k=1$ & $k=2$ \\
\hline$l=2$ & 2 & 2 \\
\hline
\end{tabular}

Table 4 The $k$ period route $j$ corresponds to the number of ship berths $x_{k j}^{l}$ (Ship)

\begin{tabular}{cccc}
\hline \multicolumn{2}{c}{ Period $k$} & & $k=1$ \\
\cline { 1 - 2 } Berth type $l$ & Route $j$ & & $k=2$ \\
\hline$l=1$ & $j=1$ & 7250 & 15000 \\
$l=2$ & $j=1$ & 1200 & 2250 \\
\hline
\end{tabular}

Table 5 Port planning investment other data

\begin{tabular}{cccc}
\hline Berth type $l(l=1,2)$ & $b_{l}(100$ million $¥)$ & $q_{l 0}$ & $A_{l}$ \\
\hline $4000 \mathrm{TEU}$ & 1 & 10 & 25 \\
$12000 \mathrm{TEU}$ & 2 & 2 & 12 \\
\hline
\end{tabular}

We put the above data into port investment optimization model (14) (Respectively to empower the two objective function, supply-demand matching function weighted $\eta_{1}$, port comprehensive cost function weighted $\eta_{2}$, and $\eta_{1}+\eta_{2}=1$ ), and use the software Matlab, we get the optimal investment planning result of container port in the 15 years of 2014 to 2023, as shown in Table 6.

Table 6 Investment optimal results $q_{l k}$

\begin{tabular}{ccc}
\hline$\eta_{1}=1 ; \eta_{2}=0$ & $k=1$ & $k=2$ \\
\hline$l=1$ & 2 & 1 \\
$l=2$ & 1 & 0 \\
\hline \hline$\eta_{1}=0.5 ; \eta_{2}=0.5$ & $k=1$ & $k=2$ \\
\hline$l=1$ & 1 & 0 \\
$l=2$ & 1 & 1 \\
\hline \hline$\eta_{1}=0 ; \eta_{2}=1$ & $k=1$ & $k=2$ \\
\hline$l=1$ & 0 & 2 \\
$l=2$ & 2 & 1 \\
\hline
\end{tabular}




\section{Conclusions}

In this paper, using the port supply and demand balance and comprehensive cost as the two main optimization goals, and the ecological carrying capacity and the port profit and loss as the constraints, a port multi period investment decision optimization model is built up by means of dynamic programming. It helps to prevent the port resources waste and destruction of the ecological environment, and has the reality instruction significance.

The model has three characteristics as follows: Firstly, it reflected the matching principle of port group supply and demand, which solves the problem of port unoccupied or overload operated. Secondly, it has considered port's ecological carrying capacity. Bringing ecological carrying capability into port investment optimization strategy reflected the idea of people oriented and protecting environment, which can optimize investment strategy efficiently. Thirdly, it reflected the principle that port investment and profit should be balanceable. By controlling port investment cost directly, it resolved the disadvantage of aimless investing for scopeneglecting port operational profit, and reflected the operational discipline of port investment efficiently.

\section{References}

[1] Shu H F. China's current port investment potential risk analysis. China Ports, 2006(2): 23-24.

[2] Zong S. Chinese port investment potential risks and investment value analysis. Transportation Construction Management, 2006(9): 4-6.

[3] Goss R O. Towards an economic appraisal of port investment. Journal of Transport Economics and Policy, 1967(1): 249-272.

[4] Hilde M A. Port investments in an uncertain environment. Research in Transportation Economics, 2005(13): 279-298.

[5] Yang X Y. Use of a comprehensive cost of the best container terminal equipment, the scale of investment. Port Engineering Technology, 1995(2): 17-21.

[6] Li J Z, Ni W F, Fang C X. Artificial neural network model of harbor investment aided decision-making by Genetic Algorithm. Chinese Journal of Management Science, 2000, 8(1): 56-60.

[7] Ding Y Z. Simulation and integer programming based on multi-terminal container port handling equipment investment model and its application in Shanghai. Journal of Shanghai Maritime University, 2006(27): 2126.

[8] Wang C X, Jiang L K. Bi-level programming based optimization on regional port inland transportation network. Journal of Industrial Engineering Management, 2008, 22(4): 67-71, 81.

[9] Allahviranloo M, Afandizadeh S. Investment optimization on port's development by fuzzy integer programming. European Journal of Operational Research, 2008, 186(1): 423-434.

[10] Zhang L M, Li S B, Gong H, et al. Application of environmental risk analysis in harbor master plan environmental impact assessment. Navigation of China, 2006(2): 91-95.

[11] Liu L, Ma M F, Yang F. Countermeasures responding to environmental problems in nation's part ports planning. China Water Transport, 2007, 7(2): 21-24.

[12] Kuang H B, Li H Z. Chinese port X-efficiency measurement. Systems Engineering - Theory \& Practice, 2009, 29(2): 1-9.

[13] Koh Y K. Optimal investment priority in container port development. Maritime Policy \& Management, 2001, 28(2): 109-123.

[14] Shneerson D. Investment in port systems: A case study of the Nigerian ports. Journal of Transport Economics and Policy, 1981(15): 201-216.

[15] Lew A, Mauch H. Dynamic Programming. Springe-Verlag, New York, 2007.

[16] Qiu Y Z, Chen S F. Multi-objective optimization of comprehensive transportation network management based on modified particle swarm algorithm. Journal of Management Sciences in China, 2008, 11(6): 43-50.

[17] Wayne K T. An economic theory of the port. Research in Transportation Economics, 2006(16): 43-65. 